\title{
Hierarchies of engagement and understanding: Community engagement during archaeological excavations at Khao Toh Chong rockshelter, Krabi, Thailand
}

\author{
Ben Marwick, Department of Anthropology, University of Washington, USA \\ Rasmi Shoocongdej, Faculty of Archaeology, Silpakorn University, Thailand \\ Cholawit Thongcharoenchaikit, Natural History Museum, National Science Museum, Thailand \\ Boonyarit Chaisuwan, Fine Arts Department, Thailand \\ Chaowalit Khowkhiew, Faculty of Archaeology, Silpakorn University, Thailand \\ Suengki Kwak, Department of Anthropology, University of Washington, USA
}

\section{Introduction}

In this chapter we present a case study showing an explicit strategy for local community engagement at an archaeological excavation in southern Thailand. We show how we tailored our approach to engagement to suit different sections of the local community. Our experience and strategies are probably familiar to many archaeologists working in the Southeast Asian region who have independently converged on similar approaches. We review the history of cultural heritage management in Thailand and show that while government policy has focussed resources on tourism at monumental sites, academic work has been most progressive in pioneering local community engagement at archaeological sites. Inspired by this progress, this chapter aims to provide a basic template for public engagement at various scales by explicitly documenting our strategies of local engagement at an excavation we conducted in Peninsular Thailand. We describe a model of understandings of archaeology that we found useful to strategise our engagement with the public. By providing this template we hope to make the process of promoting cultural engagement at archaeological excavations more effective and efficient for future projects.

\section{Background to cultural heritage management in Thailand}

Unlike its neighbours, Thailand has never been colonised. This means that the early years of archaeology and cultural heritage conservation in Thailand have taken a different path, especially compared to Vietnam and Cambodia where the École française d'Extrême-Orient of the French government strongly influenced the development of research and conservation of prehistoric 
sites (Glover 1999; Stark and Griffin 2004). Instead, a series of isolated foreign-led expeditions reporting prehistoric archaeological sites (e.g. Evans 1926; Sarasin 1933; Malleret 1969), combined with interest of the Thai royal family in preserving ancient monuments, defined the history of cultural heritage conservation in Thailand.

Lertrit $(2000 ; 2010)$ has traced an official concern for protecting historical monuments to the reign of King Chulalongkorn (1868-1910), and during the reign of King Vajiravudh (1910 1925) a section of the Palace's religious affairs office was split off to form a fine arts department concerned especially with Buddhist monuments. In 1925 this department was moved from the palace to the National Museum, under the supervision of the Royal Council. An act of parliament in 1932 established the Fine Arts Department as a section of the Ministry of Religious Affairs, from which it later moved to the Ministry of Education and Ministry of Culture. In 1943, Field Marshal Pibulsonggram (1897-1964), then Prime Minister, set up a new university, the University of Fine Arts or Silpakorn, to train students in art, art history and archaeology to provide staff for the Fine Arts Department. Most of the early fieldwork by the Fine Arts Department of Thailand was concerned with proto-historic and historic ruins, primarily in Phimai, Lopburi and Ayuthya.

The main legal instrument that the Thai Fine Arts Department operates with is the Act on Ancient Monuments, Antiques, Objects of Art and National Museums, B.E.2504 (1961). The act is mostly concerned with the ownership and administration of ancient monuments, antiques, art objects and national museums. The focus on monumental and aesthetic qualities of ancient objects and sites is consistent with the origins of the Department in the royal palace. The early homes of the Fine Arts Department in the Ministries of Religious Affairs, Education and Culture show the close links between heritage management and the official maintenance of national narratives of Thai history and culture. Stark and Bion (2004:118) note that the modern Thai Fine Arts Department is comparable to equivalent agencies in Vietnam, Malaysia and Indonesia as one of a group of 'outstanding examples of heritage management organisations, with well-trained archaeologists and (at least until recently) adequate funding'.

With this bureaucracy in place and the improved accessibility of Thailand to foreigners after the Second World War, larger, more coordinated and more diverse archaeological research and conservation efforts appeared in Thailand (Shoocongdej 2011a). For example, the Thai-Danish Prehistoric Expedition of 1960-1962 resulted in the well-documented excavation of Sai Yok rockshelter (van Heekeren and Knuth 1967) and expeditions by Chester Gorman (1971) and his students from the 1960s onwards.

To summarise, the history of archaeological heritage management in Thailand has been focused on relatively recent prehistory and visually appealing remains, mostly because these sites and artefacts help foster and legitimise Thai national pride (Shoocongdej 2011a). Much of the current scholarly interest in the cultural heritage of Thailand continues this focus with conservation of Buddhist and Khmer monumental sites, prevention of illegal trading of antiques and development of cultural heritage tourism to promote economic growth (Peleggi 1996). A subset of this research is notable for a critique based on Buddhist ideology of contemporary Western conservation strategies (Byrne 1995; Karlström 2005). In the context of cultural engagement, the most politically and economically important element of these current interests is archaeological heritage tourism, which has become a substantial component of public engagement in Thai archaeology because of government policies enacted by the Tourist Authority of Thailand. These government priorities have been criticised as a misuse of archaeological heritage and one of the reactions to this has been a shift of focus by academic archaeologists in Thailand to strengthen local and grassroots community organisations (Lertrit 1997; 2000; Shoocongdej 2011b). In a recent review, Schoocongdej (2011b) describes four long-term archaeological research projects (Sub Champa, Pong Manao, Ban Bo Soak and Ban Rai Rockshelter) run by Thai scholars that include 
an explicit, multi-component and mutually beneficial engagement with local communities for evaluating the significance of the local archaeological heritage and conserving it. The case study we present here was inspired by the success of these projects and drew on many of their methods. We focus on the specific event of the excavation to show how a fine-grained approach to engaging with site visitors can improve understanding of local prehistory and the process of archaeology.

\section{Excavations at Khao Toh Chong: A case study in community engagement in peninsular Thailand}

Our interest in working at Khao Toh Chong was motivated by recent work that describes three viable models of the hominin colonisation of Southeast Asia: a route from south Asia along the coast of Burma; a route directly south from China into northern Thailand and a route from China into northern Vietnam (Marwick 2009). Peninsular Thailand is significant in these models because it is an area where hominins likely travelled through to colonise island Southeast Asia, regardless of which route they entered mainland Southeast Asia (Figure 1). The potential of this region to provide information on the period that we are interested in has been established by the results of excavations at Lang Rongrien rockshelter and the Moh Khiew site cluster, both in Krabi Province.

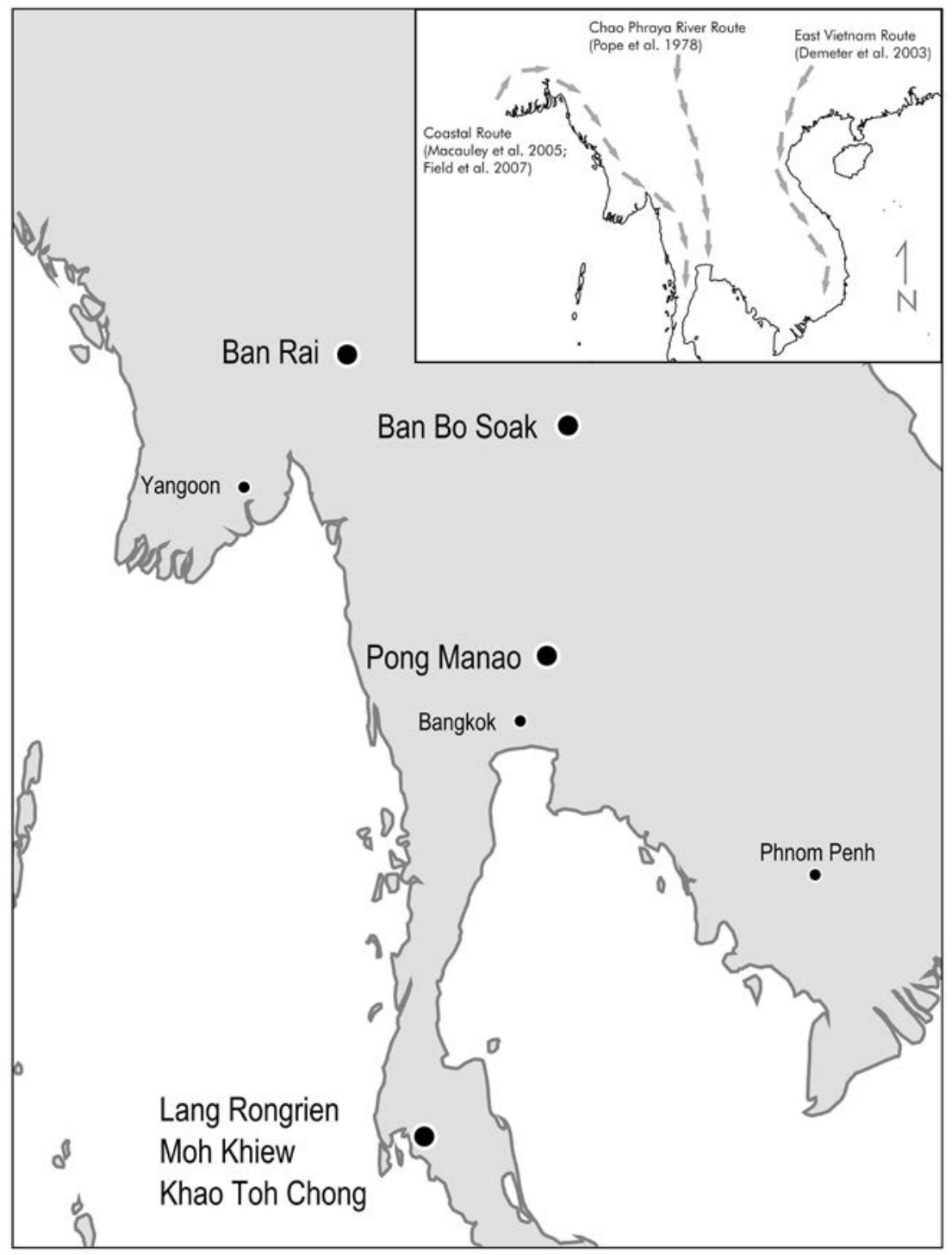

Figure 1. Map of sites discussed in the text. 
Lang Rongrien is a rockshelter in the Krabi River valley about $12 \mathrm{~km}$ east of the coast on the Malay Peninsula in Thailand. Approximately $100 \mathrm{~m}^{2}$ of the rockshelter floor - virtually the entire surface - was excavated by Anderson over 1974-1990. Anderson's excavation of Lang Rongrien is one of the pioneering contributions to the establishment of human antiquity in Southeast Asia. For its time, the level of reporting was also remarkable, however the limited detail available on chronology, stratigraphy and the lithic artefact assemblage makes it difficult to use this site to address current research priorities about human evolution, adaptation, colonisation and global diversity. Anderson's excavations did not reach bedrock but terminated in a sterile layer of limestone debris composed of rock fall from the roof of the shelter (Anderson and Mudar 2007:299). This invites the possibility that we might find deeper and older deposits in the area.

Excavations at Lang Rongrien recovered a small (36 pieces) Pleistocene assemblage of flaked stone artefacts dating to 37,265 \pm 1000 (PITT-1249). These pieces have not been analysed in detail (i.e. metric and technological data are not available) and their current location is unknown. An older radiocarbon date of 43,000 BP has been claimed by Anderson (1990) for Lang Rongrien, but this date is ambiguous because it is described in published accounts as $>43,000$ BP with no error range. As this date was at the limit of radiocarbon dating at the time, it is likely that the true age of the deposits is much older. This dating ambiguity and the small Pleistocene assemblage limit this site in its contribution to questions on human evolution and colonisation. However, these details suggest to us that sites of similar antiquity are located in the area.

Other Pleistocene sites in Krabi Province that have been excavated include the Moh Khiew site cluster where excavations have recovered well-preserved human skeletal remains dating to 25,800 \pm 600 BP (TK-933Pr) (Matsumura and Pookajorn 2005). Statistical comparisons of cranial and dental measurements of this Moh Khiew skull by Matsumura and Pookajorn suggest that the Moh Khiew specimen is most similar to Australian samples, especially the Late Pleistocene series from Coobool Creek. Excavations by Thai archaeologists began at Moh Khiew in 1990 and are currently ongoing. Many of the publications to date on Moh Khiew have been very brief and we are awaiting publication of the finds at a level of detail that is suitable to engage with questions of human behavior and adaptation. However, the presence of a second confirmed Pleistocene site in Krabi indicates that there is a high probability of new investigations revealing additional sites of similar or greater antiquity.

The site we report on here, Khao Toh Chong (KTC) rockshelter, is located about $10 \mathrm{~km}$ south of Lang Rongrien. This site was first recognised as an archaeological resource by two local school teachers who brought it to the attention of the Thai Fine Arts Department. The site is a limestone overhang at the base of a $300 \mathrm{~m}$ high karst tower in Thap Prik Village. The rockshelter is about 30 $\mathrm{m}$ long with an average of about $10 \mathrm{~m}$ from the rear wall to the dripline (Figure 2). The dripline is about $40 \mathrm{~m}$ above the ground and a series of large boulders (3-4 m high) at the dripline give excellent protection from the wind and rain as well as trapping sediment in the shelter. The surface of the rockshelter is level fine sediment with no signs of disturbance and about $10 \mathrm{~m}$ above the surrounding ground, which is about $60 \mathrm{~m}$ above sea level. Similar to Lang Rongrien, KTC has a deep multi-chambered cave system with well-preserved active speleothem formations located about $30 \mathrm{~m}$ to the west of the rockshelter. We plan to obtain a speleothem sample from this cave system to analyse as a palaeoclimate archive and complete the other proxies we are analysing.

In June-July 2011 we directed a four-week archaeological field school at KTC that included students from Thailand, Cambodia, Indonesia, Burma, the Philippines, Korea, Vietnam and the USA. The field school excavated two areas of $2 \times 2 \mathrm{~m}$ to a depth of about $2 \mathrm{~m}$ and recorded unusually well-preserved stratigraphic layers and features, including lenses of marine and freshwater shellfish. Analysis of these materials is ongoing, and our initial impressions are that the 
excavated deposit spans the entire Holocene period and late Pleistocene. There are several distinct changes in the sequence in each of the major categories of evidence we recovered. The stone artefact technology changed from polished adze flakes made from fine-grained sedimentary rock accompanied by ceramics in the upper levels to large flaked cores and flakes made from coarsegrain metamorphic rock in the lower levels. The lower levels also show a change in the faunal assemblage with the appearance of artiodactyl remains (some with cut marks) and a reduction in the remains of small mammals and reptiles that are common in the upper parts of the site. The ceramic assemblage also changes from black sherds in the upper levels to thicker, red sherds with frequent incised decorations in the lower levels and then ceramics disappear altogether when flaked cores and artiodactyl remains appear in the lowest levels. We interpret the lower levels, with their artiodactyl remains, flaked stone artefacts and absence of ceramics and polished stone artefacts, as likely to have been deposited during the late Pleistocene or early Holocene and expect radiocarbon analyses currently underway to confirm this.

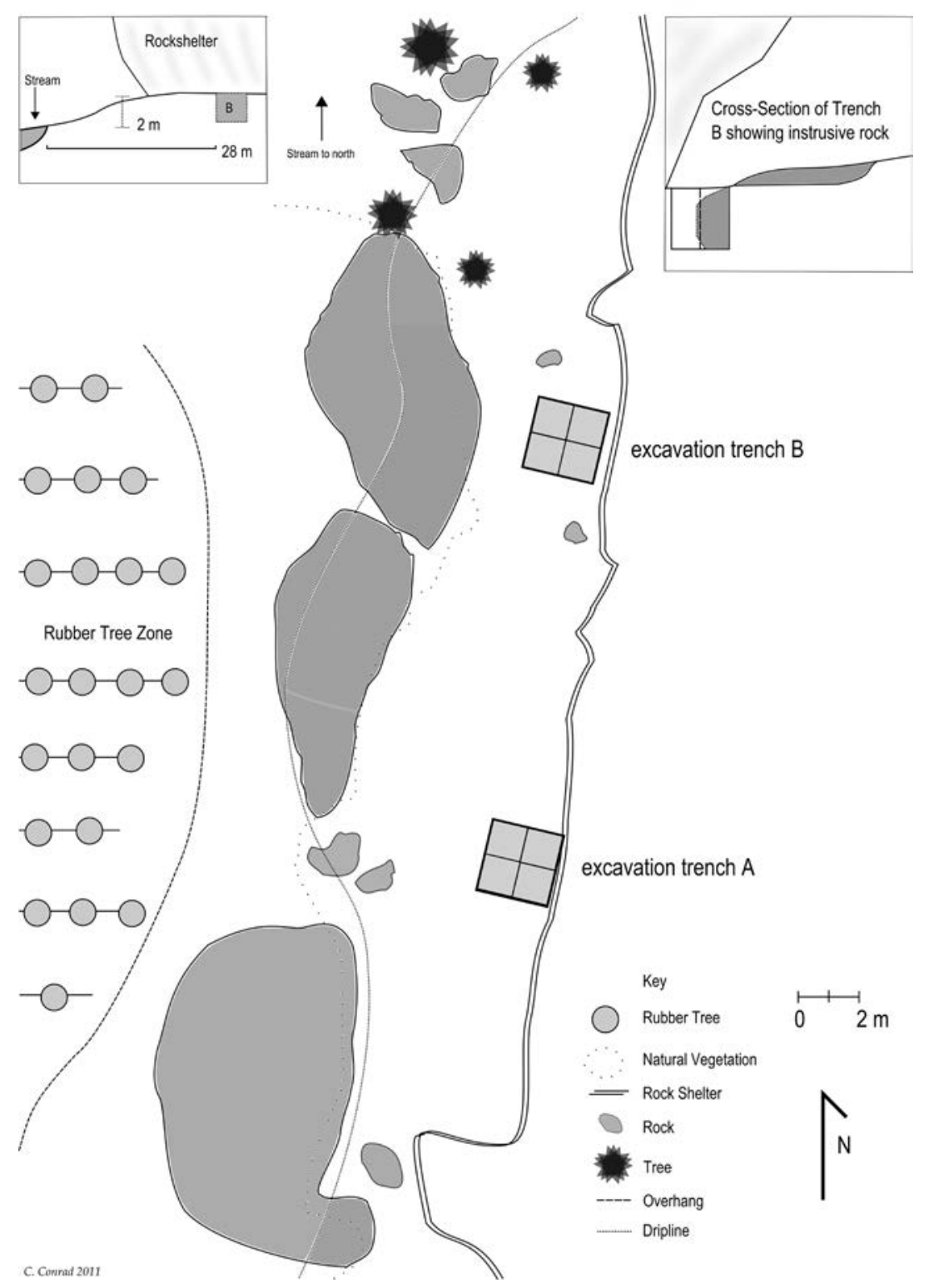

Figure 2. Plan of Khao Toh Chong rockshelter showing areas excavated in 2011.

Source: Drawn by Cyler Conrad. 
One of the features of this deposit that makes it unique amongst mainland Southeast Asian sites is that relatively few post-depositional processes have disturbed the site. For example there we did not encounter any burials, there are no animal burrows and there is very limited termite activity at this site. The most striking indication of this is a series of six shell dense layers 0.1-0.2 $\mathrm{m}$ thick that vary in the proportion of species from the upper levels to the lower levels. With further analysis we expect the taxonomic variation in these shell layers will yield information about environmental change and human adaptive responses during the Holocene. Probing to a depth of $1 \mathrm{~m}$ at the base of our excavations did not locate bedrock, so we expect continued excavations at KTC to yield a long and rich Pleistocene record, comparable to nearby Lang Rongrien and Moh Khiew.

\section{Hierarchies of engagement at Khao Toh Chong}

A near-universal feature of archaeological excavations is the crowd of onlookers who are curious to see what is being uncovered. In some cases these crowds are engaged using long-term programs such as ticket sales, guides and permanent barriers to control their movements. However, the resources for such complex visitor management are frequently unavailable. This was the case at KTC where our initial reconnaissance of the site suggested that we could expect a small number of local visitors, but after fieldwork began we received greater attention than expected. The main reason for this increase in attention was the threat posed by the expansion of a limestone quarry operating on the other side of the same karst tower where the KTC rockshelter is located. The quarry is widely regarded by local residents as disruptive because of the heavy vehicles that crowd the narrow local roads and create dangerous driving conditions. The destruction of the karst tower caused by quarrying was remarked by locals to be unwelcome because of its unsightliness. Many were concerned that expansion of the quarry might involve increased heavy vehicle traffic, sound and dust pollution, the loss of agricultural land and disruption to irrigation. As local residents became increasingly aware of the goals of the archaeological work, they realised that it might be relevant to their interests in slowing or stopping the quarry expansion.

The field school excavations at KTC attracted substantial national media attention in Thailand because we revealed that the area near the quarry contained a scientifically significant archaeological record which is threatened by proposed expansion of the quarry operations. This media attention unexpectedly multiplied the amount of local visitors and motivated us to be more strategic in our engagement with visitors with the limited resources available. Like many excavations, our visitors could be classified into four groups: school children, local residents, local government and the national media. While we gave the basic story of what we though prehistoric people were doing to everyone, to ensure maximum impact of our work we crafted slightly different messages for each of these audiences.

With the first group, the school children, we emphasised the value of competence in basic literacy and numeracy (Figure 3). Our message was that if they learn to read and count well then they get to do exciting activities like excavation and receive attention from TV crews. We also highlighted the visceral and physical appeal of the work. By inviting the children to touch ancient things as they were being recovered from the sieves, we encouraged them to vividly imagine a prehistoric person's touch on the same object. These kinds of tactile and immersive experiences seemed to be very engaging for children, perhaps because of the novelty of the idea of a time far before the present when the artefacts were made and used.

The second group were the local adult residents, with whom we most frequently engaged out of the four groups (Figure 4). We showed how the finds in our excavation gave a few insights into the quotidian details of how people used to live in the area. Some residents were impressed to see 
that their current lifestyle shared some similarities to the prehistoric lifestyle they inferred from the artefacts from KTC. The local residents were the group most interested in the possibility that the significance of our finds would support their opposition to the expansion of the nearby limestone quarry. Unlike the local children, most local adult residents had little interest in any direct physical involvement with the excavation. The local adult visitors were also the group that were most active in practicing local beliefs and superstitions at the site, arranging for Buddhist monks to pray at the excavations and a visit from a local shaman who provided an interpretation of prehistoric use of the site. Byrne (2011) notes that these types of religious activities are common at archaeological sites in most Asian countries and represent an important dimension of local cultural engagement with archaeological sites and objects.

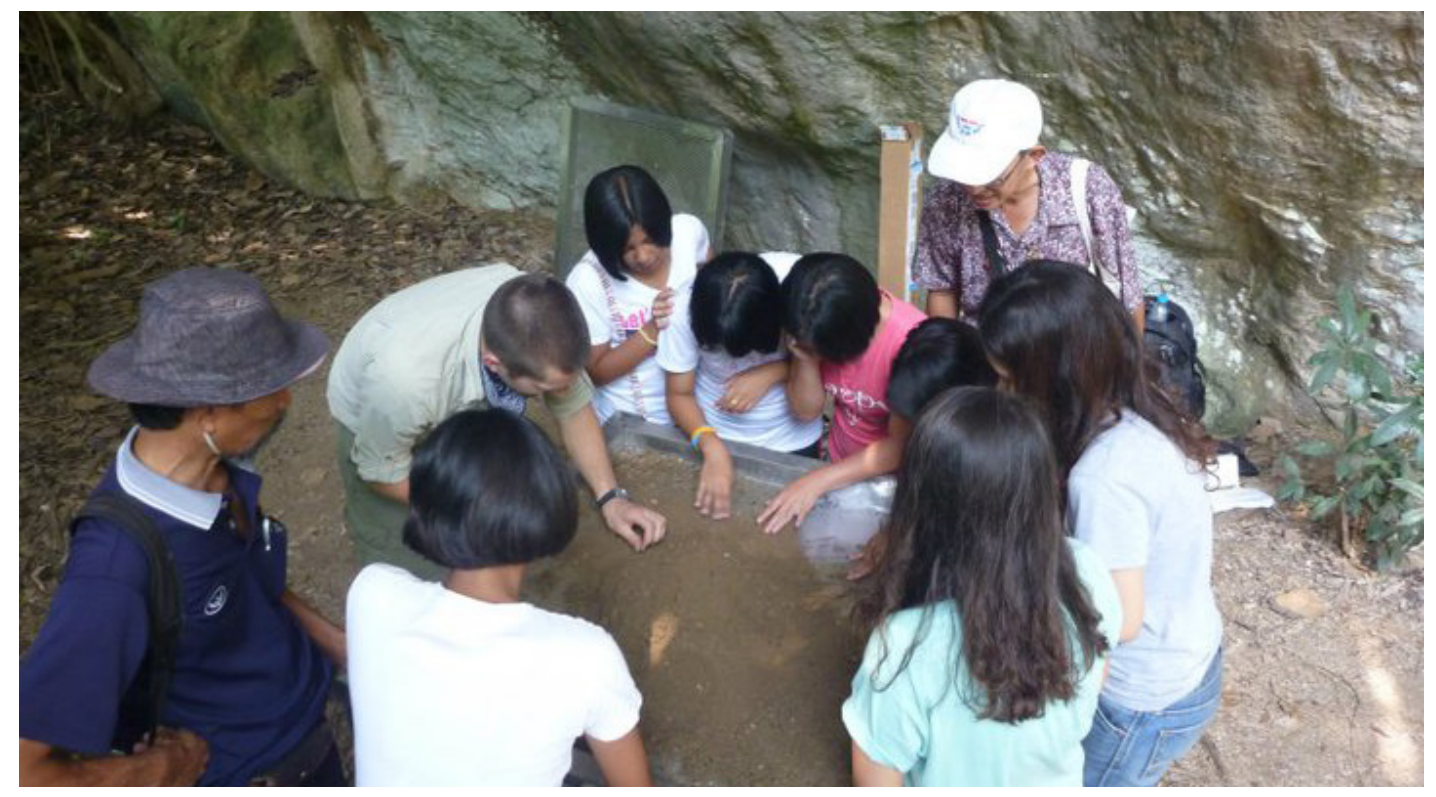

Figure 3. Local children assisting with sieving at the excavation of Khao Toh Chong.

Source: Photo by authors.

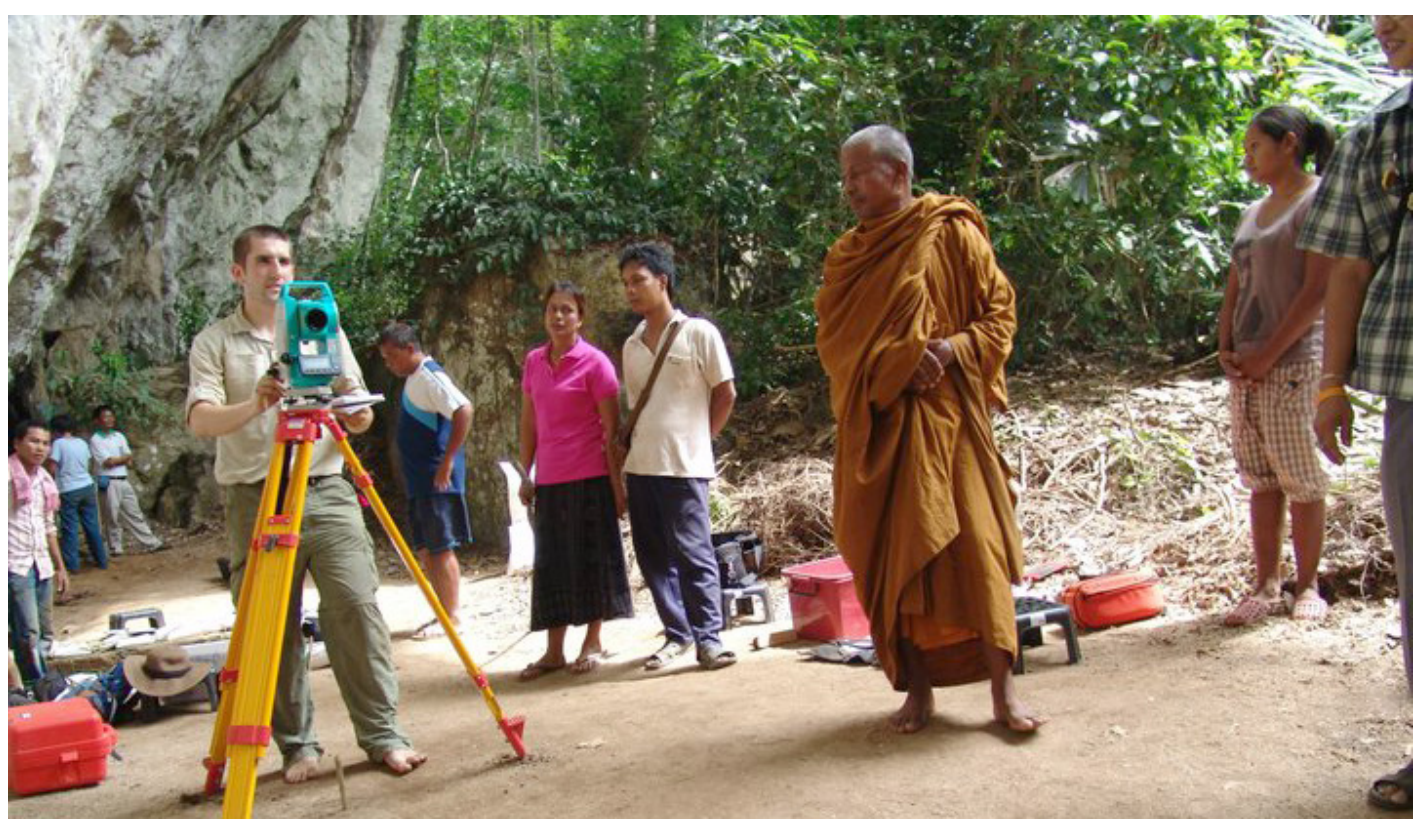

Figure 4. Local adult residents visiting the excavation at Khao Toh Chong with a monk.

Source: Photo by authors. 
The third group was local government officers. Our engagement with this group was highly formalised and distinctly different from the school children and local adult visitors. With the local government officers we focussed on communicating the broader social and economic impacts of our project. We described how Thai students and scholars were working closely with ten other nationalities, and how all participants were learning new skills and building relationships that we hoped would improve the capacity of archaeology in Thailand and the home countries of the other participants. We also demonstrated the positive economic impacts of the archaeological fieldwork resulting from hiring locals, buying local food and supplies and making minor infrastructure improvements (like building a bigger footbridge across the fields that lead to the site and installing electrical cables).

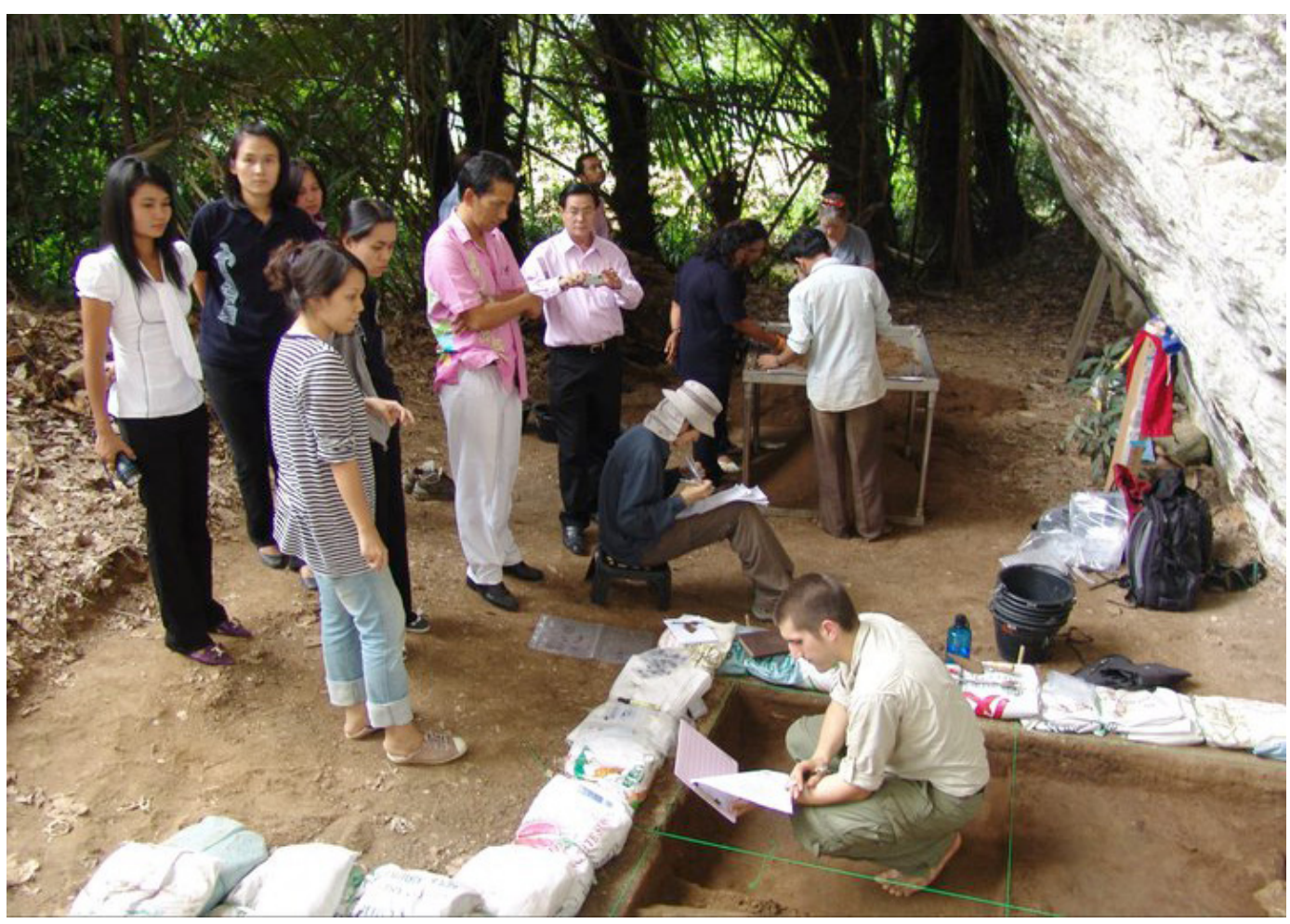

Figure 5. Government officials, in this case staff from the Krabi Office of Culture, visiting the excavation at Khao Toh Chong.

Source: Photo by authors.

The fourth group was the national television news media, whose visits were the briefest and least frequent, but most intensive because of the attention they demanded (Figure 6). Our strategy with the media was to engage with them exclusively about the scientific results of the excavation. We knew the video captured during the media visited would be edited to about ten seconds of footage, so we wanted to be sure that viewers could see we were working on basic questions about prehistoric humans as our primary activity. Although the greatest proportion of our public engagement time was spent on educational and advocacy engagement with local children and adults, we believed that for a wider audience it was important to communicate the message that our project was scientific, rigorous and controlled. There were two reasons for this, first is that the local situation of an expanding quarry is of little interest to news-watchers throughout the rest of Thailand. Second, we wanted people to get a rapid understanding of the difference between controlled archaeological excavation and looting. Our strategy was that the most effective way to demonstrate the difference between archaeology and looting in ten seconds was to show how archaeology is characterised by the use of measurement instruments, extensive documentation and slow and systematic excavation procedures. 


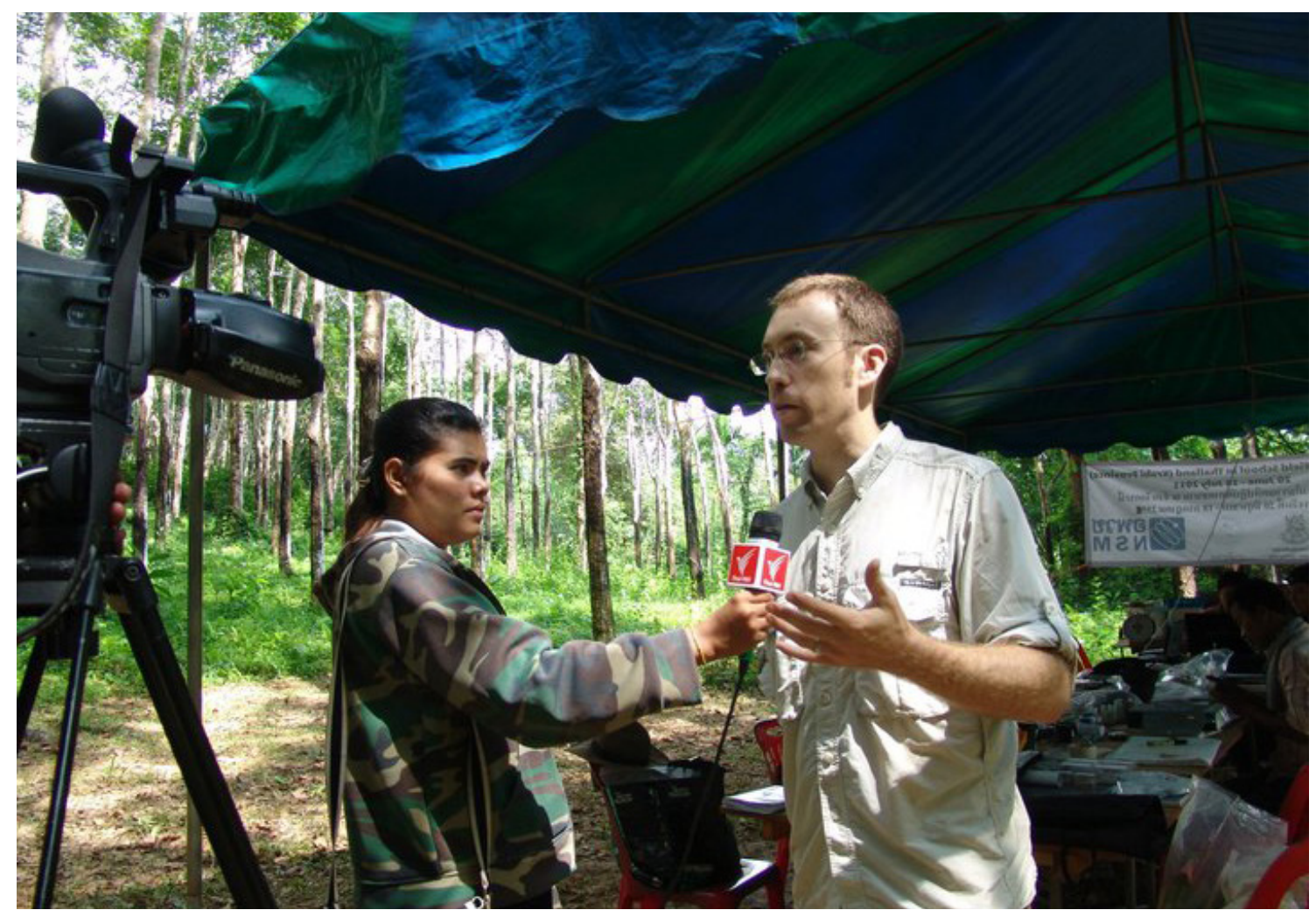

Figure 6. Staff from the Thai Public Broadcasting Service interviewing Ben Marwick at the field lab adjacent to Khao Toh Chong. All interviews were conducted in Thai.

Source: Photo by authors.

Through our engagement with these four groups we shared nearly every aspect of our activities with the public, although in a selective and hierarchical way, depending on the interests, abilities and agendas of each group (and us as archaeologists). There were also details that we had to strategically withhold from all forms of public engagement. In the upper layers of our excavations we found a very small number of valuable ancient objects. These finds were hard to hide from the local residents since they were frequently watching the excavations. The recovery of these objects created a concern that looters would come in the middle of the night to dig up the site and local backyards in search of additional finds to sell as jewellery. In response to this concern, we agreed that the valuable objects were not to be openly discussed at the site or mentioned to any visitors. We also were careful to avoid circulating their photos online, where we had been keeping an illustrated multi-lingual diary of the excavation (see http://afst11.wordpress.com/ and https:// www.facebook.com/groups/176618192390525/photos/).

\section{Hierarchies of understanding: Modelling local understandings of what archaeology is about}

Implicit in our strategy of public engagement are our expectations and hopes for how the four different groups would understand what archaeology is about. Although we did not formally survey our visitors like Lape and Hert (2011), we suspect there were probably as many different understandings of archaeology as there were individual visitors to the site. To make this diversity manageable, we found it useful to fit a three-dimensional model of archaeological understanding based on Abbott's (2004) updating of Charles Morris' (1946) classic theory of semiotic relations. The three dimensions are syntactic archaeology, semantic archaeology and pragmatic archaeology. 
Syntactic archaeology refers to the possibility that by inflicting too much of our technical details on the visitors we convey the understanding of archaeology as a set of abstract arguments about prehistoric human life. The outcome is that we contribute toward an understanding that archaeologists most value the elements of surprise, elegance or counter-intuitiveness in our accounts of prehistoric people. People holding this view of archaeology typically see it as an ivory tower game that cannot justify the use of public resources such as grant funds. Obviously we strived to discourage this type of understanding amongst our visitors. We label this a syntactic archaeology because it - unfortunately - suggests that the public understand archaeology as academic work producing explanations that do not involve any readily tractable meaning.

Semantic anthropology is a more positive understanding of archaeology, where our work is recognised as an attempt to generate meaning by reference to objects with agreed-upon meanings and truth and falsity. People holding this view understand that we can explain aspects of prehistoric life to the point where we can give a sufficient account to solve a problem. For example, when visitors ask 'what did they eat?' we pointed to the shellfish and burnt animal bones, named the species and described their habitats and give our interpretation of how the food was prepared. This way of understanding archaeology views it as a transposing activity where a question about the past is moved into the common-sense world of the immediate where it becomes immediately comprehensible. We translated a phenomenon from one sphere of analysis to another until a final realm is reached at which we are intuitively satisfied. Here we convey the understanding of anthropology as process of answering questions, which we believe was the most frequent type of understanding of what archaeology is amongst our visitors and the one we felt most comfortable promoting.

Pragmatic archaeology is archaeology that results in intervention. That is, we make an explanation of the archaeological record that allows a current issue beyond the realm of the archaeological research to be managed more effectively. Archaeology will of course never cure an epidemic or eradicate poverty, but in our case we might imagine it improving people's quality of life by limiting the expansion of an intrusive industrial operation or giving them an increased sense of belonging, community legitimacy and familiarity with the place they live by showing continuity of lifeways from prehistory into the present. This conveys the understanding of archaeology at intervention, where we produce explanations that allow action to be taken beyond the immediate context of the work. While we did not actively encourage this type of understanding of archaeology amongst our visitors, it was clear to us that many local residents hoped that the archaeological fieldwork would result in an intervention. In general, archaeologists rarely convey this pragmatic understanding to the public because we rarely encounter a narrow neck of causality (Abbott 2004:9), where archaeological work is part of a small number of mechanisms that can be identified and controlled in the scheme of causes of phenomena of broad importance to the public.

\section{Conclusion}

In this chapter we have described our strategy for engaging with different sections of the local community that visited our excavations at Khao Toh Chong. We drew on successful models of community engagement from more established archaeological projects elsewhere in Thailand. We tailored our engagement to four different groups that we identified in our visitors: local children, local adults, local government officials and national media. The specific method of engaging with each group was based on our perception of their interests and the way they appeared to understand the purpose of archaeological research. As a final observation, we note that while the development of Southeast Asian archaeology has included the incorporation of Western theories and methodologies into local archaeological practices, a distinctive practice of cultural engagement has emerged independent of Western traditions. 
In her review of the uses of archaeology in Southeast Asian countries, Shoocongdej (2011a:724) observes that Southeast Asian archaeologists appear to have a heightened awareness of their professional responsibilities to the communities and societies. The motivation for this distinctive practice comes from the belief that archaeological evidence and control over interpretations of this evidence do not belong to one particular group; instead these belong to everyone to whom to the evidence is relevant (Shoocongdej 2011b). This belief is most likely a result of Western imperial activity in Southeast Asian and Western uses of the discipline of archaeology (Shoocongdej 2007). Our hope is that more explicit documentation of these distinctive local practices, such as we have presented here, will make cultural heritage management more efficient and effective by improving cooperation and communication between stakeholders (Lertcharnrit 2010; Shoocongdej 2011a).

\section{Acknowledgements}

Thanks to the students who participated in the field school and made vital contributions to our public engagement activities: Borisut Boriphon, Jess Butler, Praewchompoo Chunhaurai, Cyler Conrad, Kim Sreang Em, Fitriawati, Anna Hopkins, Kate Lim, Supalak Mheetong, Kyaw Minn Htin, Chonchanok Samrit, Thanh Son, Rachel Vander Houwen and Hannah Van Vlack. Thanks to local residents Mr. Suthep Chantara and Mr. Niwat Watthanayommanaporn, who first brought the archaeological potential of this site to our attention. Ben Marwick was supported by a Luce/ACLS Postdoctoral Fellowship (Grant \# B9471 01 180401 7301) and an award from the Schwartz Endowment for International Education from the Office of Global Affairs, University of Washington.

\section{References}

Abbott, A.D. 2004. Methods of discovery: Heuristics for the social sciences. WW Norton and Co., New York.

Byrne, D. 1995. Buddhist stupa and Thai social practice. World Archaeology 27(2):266-281.

Byrne, D. 2011. Cultural heritage and its context in Southeast Asian local-popular culture. In: Miksic,

J. (ed.), Rethinking cultural resource management in Southeast Asia preservation, development, and neglect, pp.3-14. Anthem Press, London.

Evans, I. 1926. Stone implements from Chong. Journal of the Federated Malay States Museums 12(2):3557.

Glover, I. 1999. Letting the past serve the present - some contemporary uses of archaeology in Vietnam. Antiquity 73(281):594-602.

Gorman, C. 1971. The Hoabinhian and after: Subsistence patterns in Southeast Asia during the Late Pleistocene and early recent periods. World Archaeology 2(3):300-320.

Karlström, A. 2005. Spiritual materiality: Heritage preservation in a Buddhist world? Journal of Social Archaeology 5(3):338-355.

Lape, P. 2011. Archaeological practice in Timor Leste: Past, present and future. In: Miksic, J. (ed.), Rethinking cultural resource management in Southeast Asia preservation, development, and neglect, pp.67-90. Anthem Press, London.

Lertcharnrit, T. 2010. Archaeological resource management in Thailand. In: Messenger, P.M. and Smith, G.S. (eds), Cultural Heritage Management: a Global Perspective, pp.176-187. University Press of Florida, Gainesville. 
Lertrit, S. 1997. Who owns the past? A perspective from Chiang Saen, Thailand. Conservation and Management of Archaeological Sites 2(2):81-92.

Lertrit, S. 2000. Cultural resource management and archaeology at Chiang Saen, northern Thailand. Journal of Southeast Asian Studies 31(1):137-161.

Malleret, L. 1969. Histoire abrégée de l'archéologie Indochinoise jusqu’à 1950. Asian Perspectives $12: 43-66$.

Marwick, B. 2009. Biogeography of middle Pleistocene Hominins in mainland Southeast Asia: A review of current evidence. Quaternary International 202:51-58.

Morris, C. 1946. Signs, language and behavior. Prentice-Hall, Oxford.

Peleggi, M. 1996. National heritage and global tourism in Thailand. Annals of Tourism Research 23(2): 432-448.

Sarasin, F. 1933. Prehistoric researches in Siam. Journal of the Siam Society 26(2):171-202.

Shoocongdej, R. 2007. The impact of colonialism and nationalism in the archaeology of Thailand. In: Kohl, P. Kozelsky, M. and Ben-Yehuda, M. (eds), Selective remembrances: Archaeology in the construction, commemoration, and consecration of national pasts, pp.379-400. The University of Chicago Press, Chicago.

Shoocongdej, R. 2011a. Contemporary archaeology as a global dialogue: Reflections from Southeast Asia. In: Lozny, L. (ed.), Comparative archaeologies: A sociological view of the science of the past, pp. 707-729. Springer, New York.

Shoocongdej, R. 2011b. Public archaeology in Thailand. In: Okamura, K. and Matsuda, A. (eds), New perspectives in global public archaeology, pp. 95-111. Springer, New York.

Stark, M.T. and Griffin, B. 2004. Archaeological research and cultural heritage management in Cambodia's Mekong Delta: The search for the 'Cradle of Khmer Civilization.' Marketing Heritage: Archaeology and Consumption of the Past, 117-141.

van Heekeren, H.R. and Knuth, E. 1967. Archaeological excavations in Thailand. Volume 1. Sai Yok. Stone Age settlements in the Kanchanaburi Province. Munksgaard, Copenhagen. 